\title{
Measures of Individual Risk Attitudes and Portfolio Choice: Evidence from Pension Participants
}

\author{
Mehmet Y. Gürdal
}

Tolga U. Kuzubaş

Burak Saltoğlu

\begin{abstract}
We use a large non-student sample to test how distinct measures of risk-attitudes relate to each other, to demographic characteristics and to real-life risk taking in the financial domain. These measures, namely the Bomb Risk Elicitation Task (BRET), self-reported willingness to take risks in general, the choice in a hypothetical lottery, the score in the Domain Specific Risk-Taking (DOSPERT) scale, appear to be positively correlated and exhibit a certain degree of consistency. Furthermore, a subset is driven by similar demographic characteristics as they are related positively to gender and negatively to age. Using extensive data on the retirement portfolios of the participants during the years 2008-2014, we find that all of these measures except the BRET, are positively correlated with the riskiness of individual portfolios. We observe that the most significant correlation is observed for self-reported willingness to take risks in general.
\end{abstract}

Keywords: Retirement, Equity Allocation, Stock Market Participation, Risk Aversion, Experiment

PsycINFO Classification Codes: 3920

JEL Codes: C93, D14, D81, E2

\footnotetext{
* M.Y. Gürdal (corresponding author): Department of Economics, Boğaziçi University, Bebek, Istanbul 34342, Turkey, phone: 90-212-3597554, (e-mail: mehmet.gurdal@boun.edu.tr); T. Kuzubaş: Department of Economics, Boğaziçi University (e-mail: umut.kuzubas@boun.edu.tr); B.Saltoğlu: Department of Economics, Boğaziçi University (e-mail: burak.saltoglu@boun.edu.tr). We would like to thank Sule Alan, Nick Feltovich, Ramazan Gençay, Murat Kırdar, Richard Payne, İsmail Sağlam, Thanasis Stengos Andrea Szabo and Derya Uysal for helpful comments and suggestions. All errors are ours.
} 


\section{Introduction}

Do stable innate risk preferences exist? An affirmative answer to this question has two main implications. First, one would expect to find a substantial degree of consistency between risk preferences measured by using different experimental and survey methods. Second, these preferences would, to a reasonable extent, be related to real-life behavior in domains such as insurance, investment, smoking and driving where attitudes towards risk are expected to guide individual choices. In a recent book, Friedman et al. (2014) argue that the quest for recovering innate risk preferences from revealed choices might be a hopeless endeavor mainly because risk-taking behavior across different domains has been observed to exhibit very limited consistency and individuals' relative ranking in terms of risk-aversion is not stable or might even get reversed across different domains. Moreover, behaviors such as portfolio diversification, which is a direct implication of risk preferences expressed in the form of concave Bernoulli functions, is rarely observed.

Studies that test the consistency of risk preferences offer a set of mixed results. Dave et al. (2010) Deck et al. (2013) and Crosetto and Filippin (2015) show that there's only a limited degree of consistency between different measures of risk attitudes observed in laboratory experiments. On the other hand, Roth et al. (2016) find risk preferences to be largely consistent across two different tasks. Einav et al. (2012) compare insurance coverage and investment decisions of individuals and find evidence for a domain general component of risk preferences. Studies that aim to relate elicited risk preferences to real life behaviors also offer mixed results. Barsky et al. (1997) use responses to hypothetical questions to predict real-life risky behaviors such as smoking, drinking and holding stocks and find a significant but a small effect. Anderson and Mellor (2008) find the risk aversion coefficients elicited in the Holt-Laury task to be related to being overweight, smoking and heavy drinking, but the level of significance for this effect is only modest. Kimball et al. (2009) employ a risk tolerance proxy obtained from responses to hypothetical income gambles and show that this proxy explains differences in asset allocation across households. Kapteyn and Teppa (2011) demonstrate that an index based on responses to simple risk preference questions is a more powerful predictor of portfolio allocation compared to more sophisticated measures. Dohmen et al. (2011) find that compared to other instruments they have tried, a survey question about risk-taking in general is a better predictor of real-life risky behaviors. Similarly, Nosic and Weber (2010) find that responses to a survey question on subjective financial risk attitude are correlated positively with investment in stocks. On the other hand, Sutter et al. (2013) find experimental measures of risk attitudes to be weak predictors of field behavior. 
In this paper, using a large non-student sample, we test how distinct measures of risk preferences relate to each other, to demographic characteristics and to real life risk-taking in allocation of the retirement savings. For this purpose, we designed an online module and our participants, who are employees in a financial services group, answered questions related to risk-taking behavior and played a game with the possibility of monetary rewards.

Four distinct measures were employed to elicit risk preferences:

- The degree of risk taken in the Bomb Risk Elicitation Task (BRET), recently introduced by Crosetto and Flippin (2013).

- Self-assessment of willingness to take risks in general.

- Choice in a hypothetical lottery.

- Score in the modified version of the Domain-Specific Risk-Taking (DOSPERT) scale and the score in the financial sub-scale of this item (Blais \& Weber, 2006).

We combined the data on risk preferences with the data on the demographic characteristics of individuals and tracked their asset allocation for the years 2008-2014. We found that all of the measures correlate positively with each other, however only a subset of the measures exhibit similar relations to demographic variables. For these measures, namely self-reported willingness to take risks in general, the choice in a hypothetical lottery, the score in the DOSPERT scale, we observed a lower risk aversion among males and a higher risk aversion among older subjects. On the other hand, marital status has a negative partial correlation with risk taken in the BRET and the score in the DOSPERT scale, while having no correlation with other measures. All four of the elicited measures of risk attitudes -to varying levels of partial correlations- are related to the observed equity allocations and equity market participation. The most significant association is observed for the self-reported willingness to take risks. This result is in line with the recent findings of Dohmen et al. (2011) and Nosic and Weber (2010).

Our paper is related to previous studies on (i) the determinants of asset allocation decisions in retirement savings and (ii) the validity of survey-based and experimental measures of risk, ambiguity, and time preferences in predicting actual financial decisions. The current study complements and extends these studies in that it (i) compares a larger set of risk-preference measures, (ii) applies the methodology to a large non-student sample, i.e. pension participants with potentially different characteristics, and (iii) tracks individuals over time to control for the effects of market conditions.

The remainder of this paper is organized as follows: Section 2 provides a brief introduction to the private pension system in Turkey; Section 3 describes the design of the study; Section 4 presents the 
empirical analysis and finally, Section 5 concludes with a summary and discussion of the results. The instructions are presented in the Appendix.

\section{Private Pension System in Turkey}

The Individual Pension Saving and Investment System in Turkey was established in 2001 to complement the already-existing state social security system. Private pension system is based on voluntary participation in a defined-contribution scheme. ${ }^{\dagger}$ The ratio of private pension fund assets to GDP is approximately 5\%, much lower than the 2014 OECD average of $84.2 \%$, paving the way for future growth of the industry. In line with expectations, the size of the industry grew by $23 \%$ in 2014 , reaching 5.092 million participants with an approximate total asset value of 35 billion Turkish Liras (TL).

Contracts of the pension participants are grouped into one of three categories: individual pension contracts, group individual contracts, and non-contributory group contracts, with respective shares of $73.4 \%, 20.1 \%$ and $6.1 \%$ in 2014 . Asset allocations in individual pension contracts depend solely on the choice of participants, whereas group contracts are managed centrally, and do not allow portfolio reshuffling by individuals. Contributions to the contracts can be made in four schemes: monthly, quarterly, semi-annually or annually. The majority of contracts (95\%) are based on a monthly payment scheme. Below we briefly summarize the main regulations on the private pension system.

- Participants can modify the amount of their contribution and the payment period during the course of the contract.

- Participants can switch between pension fund companies after a period of two years.

- Participants can change the allocation of funds in the contract up to 6 times in a given year.

- Participants can hold more than one contract (with no limit on the total number).

- All contracts must be consolidated at retirement.

Approximately $79.5 \%$ of participants hold a single contract, while $15.1 \%$ have two contracts and $5.4 \%$ have at least three contracts. $\$$ Table 1 summarizes the aggregate descriptive statistics (as of 2014) for the private pension system in Turkey.

$\dagger$ This section is based on the Individual Pension System Progress Report (2014) by the Pension Monitoring Center, which is the central regulatory institution of the Pension Fund System in Turkey. We refer the reader to Individual Pension System Progress Report (2014) for further details.

$\$$ This is an interesting phenomenon specific to the Turkish Pension Fund System. However, in this paper we focus on the equity allocation in new contributions and therefore we choose to consolidate contracts to construct the average allocation to equity. 


\section{Experimental and Survey Design}

The pension company where the study was conducted is part of a larger integrated financial services group, which includes a large bank and subsidiaries in pension and life insurance, leasing, factoring, asset management services and so forth. This company is one of the largest pension fund companies in Turkey, with a participant base of approximately 971,000 in 2014 and a total asset value of 6.5 billion Turkish Liras (TL). ${ }^{\S}$ Because Turkey's pension fund industry is an emerging one, the average age of contracts is generally less than 5 years.

To introduce the study, the marketing department of the pension company e-mailed the general pool of employees in the group's companies. This initial e-mail, sent on 4 August 2014, included a brief explanation of the main tasks that participation would involve. Participants were told that the first task was a practice stage for learning the rules of a game to be played (the second task), and that in the third and final task they would be asked to respond to a series of questions. Participants were informed that each task was expected to last about 5 minutes and that the 5th, 50th, 500th, 1,000th and 2,500th participants to complete the full set of tasks would be paid the actual earnings that they had won in the game.

The recipients could click on a link provided in the e-mail to complete all the required tasks online. They had 15 days to participate. From the 8,732 recipients of the e-mail, 1,702 participants completed the full set of tasks. The winners in the draw were paid their actual earnings from the game in the form of a gift check for a well-known bookstore.

When participants clicked on the link, they first encountered a web page where they were required to enter their name and bank $\mathrm{ID}^{* *}$. They were then transferred to another page which presented the instructions for the game that would follow. The game was a replication of the Bomb Risk Elicitation Task (BRET), recently introduced by Crosetto \& Flippin (2013) and tested in a large-scale experiment. In this task ${ }^{\dagger \dagger}$, subjects decide how many boxes to collect in a 10x10 grid of 100 boxes. The participant starts to collect boxes by clicking on the "start" button and an additional box is added each second. The collecting ends when the participant clicks on the "stop" button. Each collected box increases the

\footnotetext{
$\S$ As mentioned in the introduction, MIFID in the EU imposes a set of standards on pension fund companies. These standards require firms to conduct the appropriateness and suitability assessments prior to offering an investment plan to investors. Turkey is in the process of adopting these standards in the pension fund industry. The pension fund company at which we conducted this study aims at designing a simple and effective module to assess risk preferences of participants in order to be prepared for the new regulatory framework.

** The employees in the group companies each have an ID within the banking branch of the group.

$i \dagger$ This task is essentially a variation of the Columbia Card Task (Figner et al., 2009) and Balloon Analogue Risk Task (BART; Lejuez et al., 2002)
} 
earnings by a certain fixed amount, and one of the boxes contains a bomb. The participants know that one of the boxes contain a bomb but have no information about its location. If the bomb is in one of the boxes collected, the subject loses all of the earnings. We chose this task because it is easy to understand and easy to administer in a web-based environment. In addition, the BRET provides a precise estimate of the risk-aversion coefficient. The only important difference between the original BRET study and ours is that in ours, the money earned for each box, which in our setup was equal to $10 \mathrm{TL} *$ After the participants read the instructions for the BRET, they continued to a practice screen which was identical to the actual BRET screen that followed. That is, they could press the start button to collect boxes and stop any time they wished. They were informed that this practice session would not affect their earnings in the real session. They were given no information about the location of the bomb.

On the next screen, participants were presented the three questions below. The first two, a question on risk attitude in general and a hypothetical lottery, are slight modifications of two risk-assessment questions from the German Socio-Economic Panel (SOEP) study reported in Dohmen et al. (2011) and the last one was added to the survey to serve as a proxy for the participants' wealth level.

- In general, how willing are you to take risks? (The participants indicated their responses on a scale of 0 to 10 .)

- Suppose that you inherit $100,000 \mathrm{TL}$ from a distant relative. You have an investment opportunity and in two years, the invested amount has a 50\% probability of doubling and a $50 \%$ probability of shrinking to half. How much of the inherited amount would you invest? (The participants chose among 0, 20,000, 40,000, 60,000, 80,000 and 100.000)

- What percentage of your overall wealth is invested in your pension fund? (Participants entered a number between 0 and 100 here.)

The next two screens contained 24 questions related to risk-taking behavior in various domains, e.g. ethical, financial, health and safety, recreational, social. The items used were adapted from the Revised and Improved 30-Item Domain- Specific Risk-Taking (DOSPERT) Scale (Blais \& Weber, 2006). At the request of the marketing department of the Pension Company and based on consultations with them, certain items from this original scale were excluded and others were modified (see the Appendix for a complete list of DOSPERT items used).

On the final screen, participants were given information about the location of the bomb in the BRET and their resulting earnings. They were informed about the date when the winners would be announced and were thanked for their participation.

\footnotetext{
\# At the time of the survey, 1 Turkish Lira was equivalent to 0.463 US dollars.
} 


\section{Empirical Analysis}

The responses provide several measures of individual risk attitudes. In addition to this data, we were able to retrieve basic information about the demographic characteristics of the participants via their account data in the pension company. Note, however, that demographic information and asset allocation decisions were available together for only 1,585 participants who had a retirement plan in the pension company during the years 2008-2014. We therefore conducted our analysis on this set of 1,585 participants and we provide the variable definitions in Table 2.

\section{<Table 2 about here $>$}

We first present the descriptive statistics (see Table 3) on the demographics of our participants, their choices in the BRET, their self-reported willingness to take risks, their choices in the hypothetical lottery (the inheritance question) and their combined scores on the DOSPERT scale as well as their score on the Financial scale of this item. Next, we examine the correlations among these measures and demographic characteristics of participants and employ a regression analysis to uncover how different risk measures relate to demographic factors. Finally, using a two-part econometric model, we estimate the partial correlations of the elicited risk measures with the decision to participate in the equity market and the fraction of the new contributions allocated in equities, our proxy for the actual risk-taking behavior of the participants.

\section{$<$ Table 3 about here $>$}

\subsection{Demographics and Risk Attitudes}

Of the participants for whom demographic information was available, the majority were females (61\% of our sample), and the average age was 32.5. A particular unique feature of our dataset is that it consists of responses from banking sector professionals, and $85.6 \%$ of the participants had a university degree or higher. According to the Individual Pension System Progress Report (2014), banking sector professionals constitute $6.9 \%$ of all participants in the Turkish pension system. Thus, we can expect our sample to have a relatively higher degree of financial literacy compared to the average participant in the private pension system. The gender distribution of all participants in the Turkish Pension Fund System (see Table 1 in section 2) reflects a bias towards males, with $60.4 \%$ males and $39.6 \%$ females, whereas females constituted $61 \%$ of the sample in our study. Finally, our participants had contribution levels greater than the average investor (383TL vs. 230TL). 
The number of boxes collected in the BRET, denoted by $\boldsymbol{r}_{\text {bret }}$, has an overall mean value of 47.9 and a standard deviation of 27.05. Excluding those who made inconsistent choices by collecting no boxes, 1 box or 100 boxes $^{\S \S}$, we obtained 1,509 observations, with the mean number of 45.6 boxes collected with a standard deviation of 25.07. Choices by women and men in this sample seem to be very close to each other, with men collecting 45.26 boxes on average and women collecting 45.83 . We found no significant difference between genders ( $\mathrm{p}$-value $=0.72$, Mann-Whitney test). This result contradicts with the Croson \& Gneezy's (2009) finding that women exhibit higher risk-aversion - a result which has been replicated in experiments with undergraduate subjects in Turkey (Ertac and Gurdal, 2012). The distribution of the number of boxes collected has a peak at 50; smaller peaks around multiples of 5 in this distribution are also prominent, as shown in Figure 1. Taking participants who made consistent choices, and following the same methodology as Crosetto and Flippin (2013), we classified $812(53.81 \%)$ participants as risk-averse, $87(5.77 \%)$ as risk-neutral and $610(40.42 \%)$ as riskloving***. While the percentage of risk-averse participants is very close to the value $(52.1 \%)$ found by Crosetto and Flippin (2013), the percentage of risk-neutral participants is much lower, resulting in a higher proportion of risk-seeker participants in our sample.

\section{<Figure 1 about here>}

The self-reported willingness to take risks, which we denote by $\boldsymbol{r}_{\text {soep }}$, takes values between 0 and 10 , and in our sample it has an overall mean value of 6.02. The histogram for this measure is provided in Figure 2. A breakdown by gender yields a mean value of 6.36 for men and 5.81 for women. This difference proved to be highly significant (p-value $<0.01$, Mann-Whitney test). In total, 930 subjects $(58.67 \%)$ indicated an $\boldsymbol{r}_{\text {soep }}$ value greater than 5 .

\section{<Figure 2 about here $>$}

For the hypothetical lottery question, where participants decided how much of an inherited (hypothetical) sum of 100,000 TL to invest, they chose to invest an average 50.4\% of the endowment, with $47.9 \%$ of the participants ( 759 of 1585 ) choosing to invest $60 \%$ or more of the endowment. Their choices in this task are denoted by $\boldsymbol{r}_{\text {lottery }}$, (see the histogram in Figure 3). While men chose to invest on average $51.92 \%$ of the endowment, the same value was $49.44 \%$ for women. As in the case with self-

\footnotetext{
$\S \S$ In this classification, we followed Crosetto \& Flippin (2013) for comparative purposes. Subjects who collected 100 boxes gained zero with a probability of one, and subjects who collected no boxes or one box were assumed to have stopped the game by mistake within the first second.

*** Assuming that the subjects is endowed with a power utility function $u(x)=x^{r}$, a risk-neutral subject $(r=1)$ should stop at 50, whereas $r \leq 0.98$ and $r \geq 1.021$ implies collecting less than 49 and more than 51 boxes, respectively.
} 
reported willingness to take risks, we find a significant difference between men and women in this domain (p-value $<0.01$, Mann-Whitney test).

\section{<Figure 3 about here >}

In the original DOSPERT scale (Blais and Weber, 2006), each item is an element of a sub-scale labeled as E(ethical), F(financial), $\mathrm{H} / \mathrm{S}$ (health/safety), $\mathrm{R}$ (recreational), or $\mathrm{S}$ (social), and the users are instructed to add the scores across all items of a given sub-scale to obtain the score for that domain. In our study, we used a total of 24 items, 5 of which were adopted from the financial domain. We denote the score obtained for this subdomain by $\boldsymbol{r}_{\text {dospert }(F)}$, (a histogram for these scores is given in Figure 4). The internal consistency of this sub-scale among the pool of participants is sufficiently high, with a Cronbach's alpha value of 0.73 . Since the score for each separate item is between 1 and 5 , the scores on this sub-scale took values between 5 and 25 . On average participants scored 12.56 on this subscale, with the average for men at 12.68 and 12.48 for women, with no significant difference between genders $(\mathrm{p}$-value $=0.21$, Mann-Whitney test $)$.

\section{$<$ Figure 4 about here $>$}

In addition to the financial sub-scale, we also used the combined score across all items in the Dospert scale as a separate variable in our analysis, denoted by $\boldsymbol{r}_{\text {dospert }}$ (a histogram for these scores is given in Figure 5). This combined score, simply obtained by summing up the scores of all 24 items, ranges between 5 and 120. The average score of the participants is 57.48 with standard deviation of 14.95. The average for men is 59.12 and for women 56.43 indicating a significant difference between genders as opposed to the financial sub-scale. (p-value $<0.01$, Mann-Whitney test)

\section{<Figure 5 about here>}

In Table 4, we present the correlations between the measures of risk attitudes and demographic factors employed in this study. We observe that all measures are positively correlated at varying degrees. The highest correlation between distinct measures is observed between the self-reported willingness to take risks and the investment in a hypothetical lottery ${ }^{\dagger \dagger \dagger}$ (i.e. $\boldsymbol{r}_{\text {soep }}$ and $\boldsymbol{r}_{\text {lottery }}$ ) and the self-reported willingness to take risks exhibits a relatively high correlation with all other measures. On the other hand, $\boldsymbol{r}_{\text {bret }}$ has the lowest correlation with the remaining measures of risk attitudes. A further

tit Since the financial sub-scale of DOSPERT is nested in the set of all items of this scale, $\boldsymbol{r}_{\text {dospert }}$ and $\boldsymbol{r}_{\text {dospert(F) }}$ naturally exhibits a high correlation. 
examination of the correlations between the measures of risk attitudes and demographic characteristics reveals that all measures, except $\boldsymbol{r}_{\text {bret }}$ and $\boldsymbol{r}_{\text {dospert }(F)}$ are negatively correlated with age at $1 \%$ significance level ${ }^{\text {t+. }}$. As for the gender, there is a significant and positive correlation between being male and $\boldsymbol{r}_{\text {soep }}$, $\boldsymbol{r}_{\text {lottery }}$ and $\boldsymbol{r}_{\text {dospert }}$. Finally, being married is negatively associated with $\boldsymbol{r}_{\text {soep }}, \boldsymbol{r}_{\text {dospert }}$ and $\boldsymbol{r}_{\text {dospert( }(\boldsymbol{F})}$. Combining these findings, we observe that being male is generally associated with lower risk aversion, while the opposite is true for older people and people who are married. Moreover, $\boldsymbol{r}_{\text {soep }}$, arguably the simplest risk attitude measure we have in this study, turns out to have a significant correlation with all demographic characteristics.

\section{$\langle$ Table 4 about here $>$}

\subsection{Equity allocations}

Having described the different measures of risk-attitudes $\left(\boldsymbol{r}_{\text {bret, }}, \boldsymbol{r}_{\text {soep }}, \boldsymbol{r}_{\text {lottery }}, \boldsymbol{r}_{\text {dospert }}, \boldsymbol{r}_{\text {dospert }(F)}\right)$ elicited through responses, the next step is to obtain a measure for the portfolio risk of the participants through the allocation of assets in their retirement plan(s). Our data on investments in pension funds covered the 2008-2014 period. We use the annual averages of equity allocation in new contributions as our measure of portfolio risk ${ }^{\S \S}$. For each year, annual averages are calculated for participants who had made a contribution for 12 consecutive months; the remaining observations are dropped. As indicated in section 2, a participant in the Turkish private pension system with an active account in a pension company is allowed to have multiple retirement plans and can manage each of these plans separately. For each retirement plan, the participant chooses the contribution amount, the contribution frequency (monthly, quarterly or yearly) and the allocation of contributions across the available investment funds offered by the pension company. For each fund, the average proportion invested in equities in a given year is provided by the pension fund company and we calculate the resulting equity allocations by considering investments in all plans to which a participant contributed in the associated time $\operatorname{period}^{* * * * *}$.

$\$ \boldsymbol{r}_{\text {bret }}$ and age has a positive correlation at $10 \%$ level of significance.

$\S \S \S$ For most of the participants, new contribution allocation also applies to the existing funds in their retirements savings. However, pension fund system in Turkey allows participants to modify the asset allocation of new contributions without modifying the existing savings. In addition to this, participants are allowed to sell any fraction of the existing savings at any time during the year. Consequently, we decided to use the new contribution allocations as the proxy for financial risk-taking behavior. Bajtelsmit and Vanderhei (1997) states that (pp. 60): "The account balance allocation is obviously a better indicator of the overall riskiness of the portfolio, but the current contribution allocation is more likely to capture the changes that are made in response to changing life circumstances, such as job tenure, age, and accumulated wealth."

**** Starting from 2013, a state subsidy is directly paid to participant's account, at a rate of $25 \%$ of the total contributions (25\% of the gross annual minimum wage, approximately 3500TL, in a given year). This subsidy is kept in a sub-account and evaluated in mutual funds chosen by the Undersecreteriat of the Treasury. Full eligibility for these subsidies and the resulting returns requires being over age 56 and having stayed in the system for 10 years. People who have stayed less than 
In Table 5 we present a summary of the statistics on the equity allocations of the participants. We observe that equity investments are generally relatively low compared to those reported for developed countries. Overall, participants invested approximately $16 \%$ of their new contributions in equities, while this value is $40.5 \%$ in Agnew et al. (2003) and 78\% in Iyengar and Kamenica (2010), both of whose studies use the US data. In addition, while equity allocations appear to concentrate at the two extremes (0\% or $100 \%$ ) in Agnew et al. (2003), our data reveals a concentration only around $0 \%$, with almost no observations on the other extreme. Specifically, 24.8\% (885 out of 3,571) of the annual averages are zero, suggesting a relatively low rate of participation in equities. We also observe a substantial amount of variation in equity share across years, with annual averages lowest in 2009 and highest in 2011. This pattern is nearly identical to the aggregate pattern for pension participants (see Table 1 in section 2).

\section{$\langle$ Table 5 about here $>$}

While the average annual equity allocation in new contributions is $19.2 \%$ for men, women exhibit a lower likelihood of investing in equities, with an annual average of $14.2 \%$. This result is in line with the gender difference found for the self-reported willingness to take risks. Age seems to have a significant effect on the portfolio risk, with younger participants having a higher equity share in new contributions.

\subsection{Empirical Strategy and Estimation}

The next stage of our analysis aims at capturing how distinct measures of risk attitudes relate to each other, to demographic characteristics and to real-life risk taking behavior in the financial domain (definitions of the variables provided in appendix?. Using simple correlations, we have showed that (see Table 4) all measures employed in the study are positively correlated to each other, indicating that there is a certain degree of consistency among different measures of risk attitudes. However, with respect to the association between our measures and demographics, i.e. gender, marital status and age, internal consistency shrinks to a subset of risk measures. We observe a negative correlation with age and a positive correlation with being male for the measures $\boldsymbol{r}_{\text {soep }}, \boldsymbol{r}_{\text {lottery }}, \boldsymbol{r}_{\text {dospert }}$ but no significant correlation for $\boldsymbol{r}_{\text {bret }}$ and $\boldsymbol{r}_{\text {dospert }(F)}$. For the marital status, a negative and significant correlation exists with the measures $\boldsymbol{r}_{\text {soep }}, \boldsymbol{r}_{\text {dospert }}$ and $\boldsymbol{r}_{\text {dospert(F) }}$ and no significant correlation for the other measures.

10 years in the system are eligible for a certain percentage of these subsidies (15\% for 3 years, $35 \%$ for 6 years etc.). We do not include the state subsidy among new contributions, however, when included this has no qualitative effect on our results. 
As a further elaboration of this dimension, we pursue an OLS estimation of different risk measures on the demographic characteristics to obtain partial correlations. Estimation results are presented in Table 6. We also use a dummy variable indicating an administrative position in the company, a dummy variable indicating a college degree or more, and the average of the contributions to the retirement savings as control variables in our regressions. The results are reminiscent of the ones obtain from the Spearman correlations presented in Table 4. Among the five measures, only $\boldsymbol{r}_{\text {soep }}$, $\boldsymbol{r}_{\text {dospert }}$ and $\boldsymbol{r}_{\text {lottery }}$ seem to be driven by similar demographics ${ }^{\dagger \dagger \dagger \dagger}$, however, $\boldsymbol{r}_{\text {dospert }(\boldsymbol{F})}$ has no significant partial association with demographic factors and in the model for $\boldsymbol{r}_{b r e t}$, joint significance of the partial effects fails the F-test, i.e. there is no significant relation between $\boldsymbol{r}_{\text {bret }}$ and the set of demographic and control variables. One important point to note is that the combined score in the DOSPERT scale $\left(\boldsymbol{r}_{\text {dospert }}\right)$ have a significant relation with demographic factors but no such significant association exists for the score on the financial sub-scale $\left(\boldsymbol{r}_{\operatorname{dospet}(\boldsymbol{F})}\right)$ even though the latter is nested in the former. Furthermore, $\boldsymbol{r}_{\text {dospert }(F)}$ is the only measure which is significantly related to the average amount of contributions, which proxies the financial situation of the participant.

\section{$<$ Table 6 about here $>$}

Finally, we aim to uncover the relation between the risk attitude measures and real-life risk taking behavior measured by the average annual equity allocation in new contributions. To this end, we pursue a strategy involving a two-part model. In particular, the (binary) decision to participate in the equity market is estimated using a Probit model and subsequently, the amount of equity holding is estimated using a truncated OLS regression. $\$ *$ Our dataset covers the period between 2008 and 2014 and our set of control variables is as follows: gender is a dummy variable equal to one if the participant is male, and zero otherwise; marital status takes the value one if the participant is married, and zero otherwise. College is a dummy variable which is equal to one if the participant has an education level higher or equal to college and zero otherwise. $a g e_{i, t}$ is taken as age of the participant $i$ in the beginning of year $t$. Income is not readily available ${ }^{\S \S}$ for which reason we use the logarithm of the annual average of the monthly contributions of the participant as a proxy for income. In each

\footnotetext{
${ }_{T i \dagger \dagger}$ Except for the marital status. For $\mathrm{r}_{\text {soep }}$ and $\mathrm{r}_{\text {lottery }}$ the partial regression coefficient is negative but insignificant.

+1* Another commonly used modeling approach in the literature is the Tobit model which puts restriction on the parameters which can be directly tested against the two-part model using a likelihood ratio test as the Tobit model is nested in the latter. We conduct likelihood ratio tests, for alternative specifications and show that the restrictions of the Tobit model are not valid; hence the two-part model provides a better representation of the data generating process. Yet another approach is the fractional response model since our variable of interest is the fraction of equity investment. We have also estimated the relation using a fractional response model and observe that coefficient estimates do not differ. Furthermore, we have employed Panel RE and Panel Tobit estimations to see the effects of individual heterogeneity in our empirical analysis, and again observe that our estimates remain robust. Estimation results from alternative models are available from authors.

$\S \S \S$ Income level is self-reported and mostly missing for a significant fraction of our sample. We also do not have information on the monthly wages of the participants.
} 
regression, we use time fixed effects to capture time-varying common trends. In our estimations, we use alternative specifications to identify the differential impacts of our measures of risk attitudes on the realized equity allocation.

\section{$\langle$ Table 7 about here $>$}

The results of the Probit model are provided in Table 7. In columns (I), (II), (III), (IV) and (V), we separately include the measures of individual risk attitudes in the model and in column (VI) we include all measures ${ }^{* * * * *}$ together, while retaining the same set of control variables. Our results reveal that age and $\log$ of contributions have significant effects with the expected signs, as the probability of investing in equities decreases with age and increases with the size of contributions, however, gender and marital status do not exhibit a significant effect for all specifications. When included separately in the regressions, all measures of risk attitudes except $\boldsymbol{r}_{\text {bret }}$ and $\boldsymbol{r}_{\text {dospert }}$ have a significant effect (columns (II), (III), (IV)) on the probability of investing in equities where the largest marginal effect is observed for the self-reported willingness to take risk, $\boldsymbol{r}_{\text {soep, }}$, i.e. one point increase in the $\boldsymbol{r}_{\text {soep }}$ score leads to a three percent increase in the probability of participation. When we include all measures together, only the partial coefficient of the self-reported willingness to take risks remains significant, which suggests that this measure contains some additional information not present in other measures and correlated with the observed risk-taking behavior.

\section{$\langle$ Table 8 about here $>$}

Next, we estimate a pooled OLS regression on the truncated sample involving only participants invested a positive amount in equities. ${ }^{\dagger \dagger i \dagger \dagger}$ We use the same set of specifications and control variables as in the Probit model described above. Estimation results are presented in Table 8. We observe that age, gender and the amount of contributions have significant partial regression coefficients and carry the expected sign in all specifications. All measures of risk attitudes, except $\boldsymbol{r}_{\text {bret }}$, exhibit a significant association with the equity allocation. Similar to the results of the Probit estimations, the specification (VI), which includes all measures of risk attitudes as covariates, reveals that the sole measure that turns out to have a significant partial regression coefficient is the self-reported to willingness take risks, i.e. $\boldsymbol{r}_{\text {soep }}$.

***** Except the score in the DOSPERT including all items to avoid multicollinearity.

$\because+i \dagger$ In our estimations, we allow for heteroscedasticity and arbitrary correlation within observations from each participant, accordingly we use robust standard errors clustered at the participant level. We also include time fixed effects to control for common trends in the sample period which allows us to disentangle our measures of risk attitudes from an overall increase or decrease in risk appetite. Our estimation results are robust to panel random effects estimations for alternative specifications controlling for individual heterogeneity. 
In Table 7-8, we presented the marginal effects obtained separately from the Probit regression and the pooled OLS regression, which constitute the first and the second parts of our two-part model. In Table 9, we provide the combined marginal effects of the covariates from both parts. ${ }^{+1+t+1}$ By doing so, we aim to investigate whether some correlations of covariates with the observed risk-attitude cancel out when we aggregate the effects from two parts. Our results reveal that this is not the case, as the partial regression coefficients have the same sign for both the participation and the equity allocation decisions ${ }^{\S \S \S \S}$.

\section{$\langle$ Table 9 about here $>$}

\section{Conclusion}

In this paper, we study the risk preferences of a relatively large group of pension participants and their asset allocation decisions for the years 2008-2014. Our main goal is to identify how distinct measures of risk attitudes relate to each other, to demographic characteristics and to real-life risk taking behavior in the financial domain. We utilize four prominent measures to elicit risk preferences: self-reported willingness to take risks, investment in a hypothetical lottery, the Bomb Risk Elicitation Task (BRET) and the Domain-Specific Risk Taking (DOSPERT) scale.

Simple correlations reveal that the measures of individual risk attitudes exhibit internal consistency, suggesting that they can potentially be utilized in ranking individuals with respect to their risk preferences. Our next question is whether the consistency revealed by the positive correlations also imply that the risk attitudes are shaped by similar demographic factors. In this case, we obtain a weaker results: Self-reported willingness to take risks, investment in the hypothetical lottery and the combined DOSPERT score exhibit consistent partial correlations as they are all negatively related to age and positively related to being male. The score in the financial sub-scale of DOSPERT exhibits no significant correlation with demographic factors, but a positive correlation with average contributions, suggesting that the score is, to a larger extent, related to overall financial situation of the individual rather than being a measure of risk preferences. The score in the BRET seems to be positively correlated to age, inconsistent with other measures, and negatively correlated to being married, consistent only with the combined score in DOSPERT.

$4+1+$ Estimation of the combined marginal effects is implemented using STATA "twopm" routine. These marginal effects are comparable to the ones in a Tobit model except we are relaxing the restrictive assumption of the Tobit model on the parameters.

$\S \S \S \S$ Our results reveal that the signs and magnitudes of the partial regression coefficients are robust to estimating the regressions separately (two-part model) or jointly (Tobit, Fractional Response models, combined marginal effects). Estimation results regarding to the other methods are available upon request from the authors. 
In the final part of our empirical analysis, we try to understand whether different measures of risk attitudes are associated with real life risk-taking, measured by the annual averages of equity allocation in new contributions. All four of the elicited measures of risk attitudes -to varying levels of partial correlations- are related to the observed equity allocations and equity market participation. The most significant association is observed for the self-reported willingness to take risks. It is surprising that the response to the simple question of "In general, how willing are you to take risks?" remains the best predictor of the actual risk-taking behavior under the presence of more complex methods to measure risk preferences. Our findings lend support to those of Dohmen et al. (2011) and Nosic \& Weber (2010), whose studies demonstrate the strong associations of subjective assessments of risk preferences with real-life risk taking. Furthermore, we extend the current literature on the association of risk measures and observed risk-taking behavior by tracking participants over time and controlling for time-varying common effects in our estimation, which we believe brings robustness to our analysis as we control for the effect of changing market conditions on real-life risk taking. Finally, we should note that our sample was drawn from a group of people working in the financial industry. Assessment of the risk preferences of a less financially literate group is left for a future study.

Why does the general risk assessment work well in our case? We argue that there might be two main reasons for this finding. First, the response of this question might work as a personal account and simply be a reflection of how the participant behaved in her past decision. This, in turn, yields a substantial correlation between this variable and actual financial decisions. Second, since our study is conducted across a pool of people in financial sector, it is reasonable to expect a common understanding of the term "risk-taking" among our subjects, who have followed similar career paths and use similar investment instruments. Friedman et al. (2014) argue that innate risk preferences are not directly observable and they are also difficult to access indirectly. While this difficulty is partially confirmed by the mixed results coming from previous studies, it is mitigated when working with subjects who have a common understanding of risk-taking. 


\section{References}

[1] Agnew. J. Balduzzi. P. \& Sunden. A. (2003). "Portfolio choice and trading in a large 401 (k) plan." American Economic Review. 93(1), 193-215.

[2] Agnew. J. (2010). "Pension Plan Behavior" in Behavioral Finance. H. Kent Baker and John Nofsinger (eds.), Hoboken, NJ: John Wiley \& Sons, Inc., 2010.

[3] Ameriks. J. \& Zeldes. S. P. (2004). "How do household portfolio shares vary with age." Working paper, Columbia University.

[4] Bajtelsmit, V. L., Bernasek, A., \& Jianakoplos, N. A. (1999). "Gender differences in defined contribution pension decisions." Financial Services Review, 8(1), 1-10.

[5] Bajtelsmit, V. L. \& VanDerhei, J.L. (1997). "Risk Aversion an Pension Investment Choices.” in Positioning Pensions for the Twenty-First Century, Michael S. Gordon (ed.), Philadelphia: University of Pennsylvania Press

[6] Barsky. R. B., Kimball. M. S., Juster. F. T. \& Shapiro. M. D. (1997). "Preference parameters and behavioral heterogeneity: an experimental approach in the health and retirement survey." Quarterly Journal of Economics 112(2), 537-579.

[7] Bateman, H., Eckert, C., Geweke, J., Louviere, J., Satchell, S., \& Thorp, S. (2015). "Risk Presentation and Portfolio Choice.” Review of Finance, forthcoming.

[8] Benartzi, S., \& Thaler, R. H. (2001). "Naive diversification strategies in defined contribution saving plans." American Economic Review, 91(1), 79-98.

[9] Blais. A.-R. Weber. E. U. (2006). “A Domain-Specific Risk-Taking (DOSPERT) scale for adult populations." Judgement and Decision Making. 1(1), 33-47.

[10] Brown, J. R., Liang, N., \& Weisbenner, S. (2007). "Individual account investment options and portfolio choice: Behavioral lessons from 401 (k) plans.” Journal of Public Economics, 91(10), 1992-2013.

[11] Crosetto. P. \& Filippin. A. (2013). "The "bomb" risk elicitation task." Journal of Risk and Uncertainty. 47(1). 31-65.

[12] Crosetto, P., \& Filippin, A. (2015). "A theoretical and experimental appraisal of four risk elicitation methods." Experimental Economics, 19(3), 613-641.

[13] Croson, R., \& Gneezy, U. (2009). "Gender differences in preferences." Journal of Economic literature, 47(2), 448-474. 
[14] Dave, C., Eckel, C. C., Johnson, C. A., \& Rojas, C. (2010). "Eliciting risk preferences: When is simple better?" Journal of Risk and Uncertainty, 41(3), 219-243.

[15] Deck, C., Lee, J., Reyes, J. A., \& Rosen, C. C. (2013). "A failed attempt to explain within subject variation in risk taking behavior using domain specific risk attitudes." Journal of Economic Behavior \& Organization, 87, 1-24.

[16] Dimmock. S. G. \& Kouwenberg. R. (2010). "Loss-aversion and household port- folio choice.” Journal of Empirical Finance. 17(3), 441-459.

[17] Dimmock, S. G., Kouwenberg, R., \& Wakker, P. P. (2014). “Ambiguity attitudes in a large representative sample." Management Science, forthcoming.

[18] Dohmen. T. Falk. A.. Huffman. D.. Sunde. U.. Schupp. J. \& Wagner. G. G. (2011). "Individual risk attitudes: Measurement. determinants and behavioral consequences." Journal of the European Economic Association. 9(3), 522-550.

[19] Donkers. B. \& Van Soest. A. (1999). "Subjective measures of household preferences and financial decisions." Journal of Economic Psychology. 20(6), 613-642.

[20] Einav. L., Finkelstein, A, Pascu. I, \& Cullen.,M., (2012). "How General Are Risk Preferences? Choices under Uncertainty in Different Domains.” American Economic Review.102(6), 2606-2638

[21] Ertac, S, \& Gurdal, M. Y. (2012). Deciding to decide: Gender, leadership and risk-taking in groups. Journal of Economic Behavior \& Organization. 83(1), 24-30.

[22] Figner, B., Mackinlay, R. J., Wilkening, F., \& Weber, E. U. (2009). “Affective and deliberative processes in risky choice: age differences in risk taking in the Columbia Card Task." Journal of Experimental Psychology: Learning, Memory, and Cognition, 35(3), 709-730.

[23] Friedman, D., Isaac, R. M., James, D., \& Sunder, S. (2014). Risky curves: On the empirical failure of expected utility. Routledge.

[24] Gough, O., \& Niza, C. (2011). "Retirement saving choices: review of the literature and policy implications." Journal of Population Ageing. 4(1-2). 97-117.

[25] Guiso, Luigi, and Monica Paiella, (2006). "The Role of Risk Aversion in Predicting Individual Behavior." in Insurance: Theoretical Analysis and Policy Implications. Pierre-André Chiappori and Christian Gollier (eds.), MIT Press: Cambridge.

[26] Handbook of Turkish Capital Markets (2015). Turkish Capital Market Association. 
[27] Huberman, G., \& Jiang, W. (2006). "Offering versus choice in 401 (k) plans: Equity exposure and number of funds." The Journal of Finance, 61(2), 763-801.

[28] Individual Pension System Progress Report (2014). Pension Monitoring Center (PMC) of Turkey.

[29] Iyengar. S. S. \& Kamenica. E. (2010). "Choice proliferation. simplicity seeking and asset allocation." Journal of Public Economics. 94(7). 530-539.

[30] Kapteyn, A., \& Teppa, F. (2011). Subjective measures of risk aversion, fixed costs, and portfolio choice. Journal of Economic Psychology, 32(4), 564-580.

[31] Kimball, M. S., Sahm, C. R., \& Shapiro, M. D. (2008). Imputing risk tolerance from survey responses. Journal of the American statistical Association, 103(483), 1028-1038.

[32] Lejuez, C. W., Read, J. P., Kahler, C. W., Richards, J. B., Ramsey, S. E., Stuart, G. L., Strong, D. R. \& Brown, R. A. (2002). "Evaluation of a behavioral measure of risk taking: the Balloon Analogue Risk Task (BART).” Journal of Experimental Psychology: Applied, 8(2), 75-84

[33] Nosic. A.. \& Weber. M. (2010). "How riskily do I invest? The role of risk attitudes, risk perceptions, and overconfidence.” Decision Analysis. 7(3). 282-301.

[34] Noussair, C. N., Trautmann, S.T., and van de Kuilen, G. (2014). "Higher order risk attitudes, demographics, and financial decisions." Review of Economic Studies 81(1), 325-355.

[35] Papke, L. E. (1998). "How are participants investing their accounts in participant directed individual account pension plans?" American Economic Review, 88(2), 212-216.

[36] Roth, B., Trautmann, S. T., \& Voskort, A. (2016). "The role of personal interaction in the assessment of risk attitudes." Journal of Behavioral and Experimental Economics. 63, 106-113.

[37] Sunden, A. E., \& Surette, B. J. (1998). "Gender differences in the allocation of assets in retirement savings plans." American Economic Review, 88(2), 207-211.

[38] Sutter. M.. Kocher. M. G.. Glätzle-Rützler. D. \& Trautmann. S. T. (2013). "Impatience and uncertainty: Experimental decisions predict adolescents' field behavior.” The American Economic Review. 103(1). 510531.

[39] Tapia, W. \& J. Yermo. (2007). "Implications of Behavioural Economics for Mandatory Individual Account Pension Systems.” OECD Working Paper on Insurance and Private Pensions, No. 11. Paris.

[40] VanDerhei, J. L., \& Olsen, K. A. (2000). "Social Security investment accounts: lessons from participantdirected 401 (k) data." Financial Services Review, 9(1), 65-78. 


\section{A. Instructions}

In this game, you will see a square composed of 100 boxes. At the beginning, press the "start" button to start collecting boxes. Every second, one box is collected automatically and you need to press "stop" to stop collecting.

You earn $10 \mathrm{TL}$ for every box that you collect. For example, if you have collected 50 boxes at the time you press "stop", that means you have collected 500TL.

But we have a warning! Behind one of these boxes, a bomb is hidden. The box where the bomb is hidden is separately and randomly determined for each participant. You will learn the place of the bomb only after you stop collecting the boxes.

If you collect the box in which the bomb is located, you will earn zero. If not, that means you have completed the game successfully and have earned the money collected in the game.

The 5th, 50th, 500th, 1000th and 2500th participant to complete the game and the survey after the game will be paid their earnings in the form of a gift check from.

In the next screen, there will be a trial stage to familiarize you with the box collection process. The earnings in the trial stage do not affect your real earnings and there will be no bomb in this stage. Good luck:)

- In general, how willing are you to take risks? (0: not willing at all, 10: extremely willing) 0-1-2-3-4-56-7-8-9-10

- Suppose that you inherit 100,000 TL from a distant relative. You have an investment opportunity and in two years, the invested amount has a 50\% probability of doubling and a 50\% probability of shrinking to half. How much of the inherited amount would you invest? 0, 20,000, 40,000, 60,000, 80,000 and 100,000).

- How much is your pension fund savings as a percentage of your overall wealth? 010203040506070 8090100

For each of the following statements, please indicate the likelihood that you would engage in the described behavior: 1- Extremely Unlikely 2- Unlikely 3- Not sure 4- Likely 5- Extremely Likely

- I would disagree with an authority figure in a business meeting. (S)

- I would bet a day's income at the number lottery. (F)

- I would pass off somebody else's work as my own. (E) 
- I would go down a ski run over a very steep hill. (R)

- I would invest in a speculative stock. (F)

- I would go whitewater rafting in high water in the spring. (R)

- I would bet a day's income in a high-stakes poker game. (F)

- I would get a tattoo at a shop that I don't know. (H/S)

- I would reveal a friend's secret to someone else. (E)

- I would drive a car without wearing a seat belt. (H/S)

- I would invest business venture. (F)

- I would take a skydiving class. (R)

- I would ride a motorcycle without a helmet. (H/S)

- I would invest in an asset offering moderate growth rates.

- I would choose a career that I truly enjoy over a more secure one. (S)

- I would speak my mind about an unpopular issue in a meeting at work. (S)

- I would sunbathe without using a sunscreen product. (H/S)

- I would go bungee jumping off a tall bridge. (R)

- I would pilot a small plane. (R)

- I would walk home alone at night in an unsafe area of town. (H/S)

- I would move to a city far away from my family. (S)

- I would leave my career in my mid-thirties and go to study abroad. (S)

- I would leave my children alone at home while running an errand. (E)

- I would not look for the owner of a wallet I found that contains 200TL. (E)

Note: The letter in parentheses (not shown to participants) represents the sub-scale that the item belongs to: $\mathrm{E}=$ Ethical, $\mathrm{F}=$ financial, $\mathrm{H} / \mathrm{S}$ : health/safety, $\mathrm{S}=$ Social, $\mathrm{R}=$ recreational. 


\section{B. Figures and Tables}

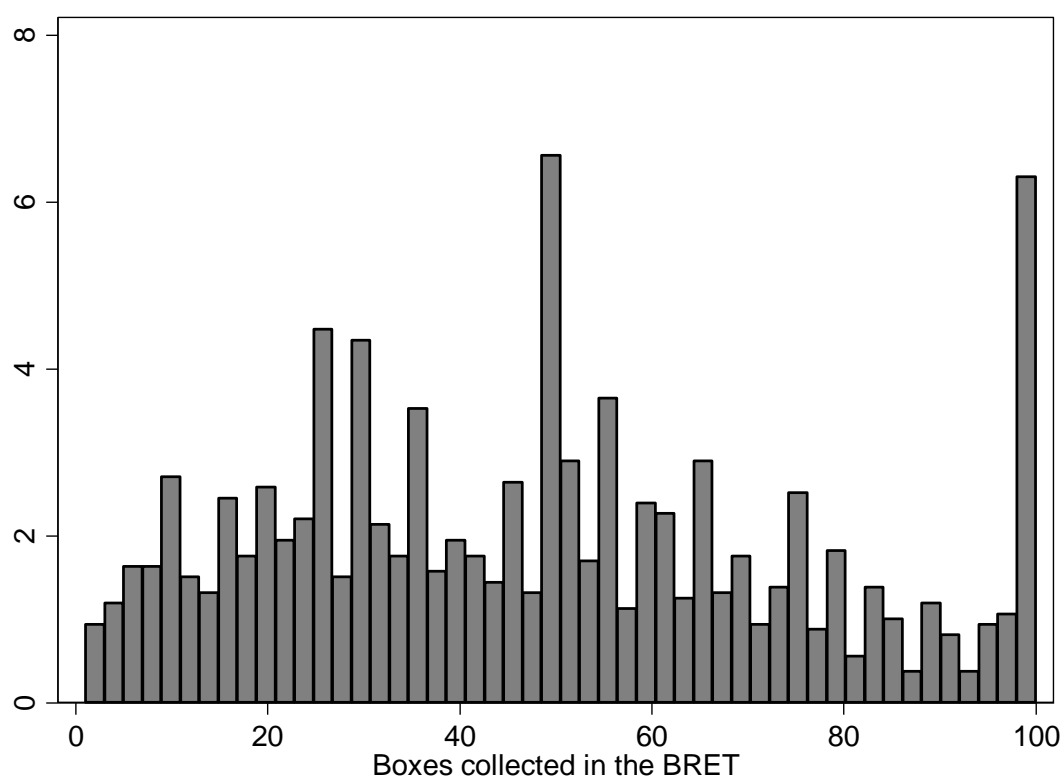

Figure 1: Histogram for Boxes Collected in the BRET

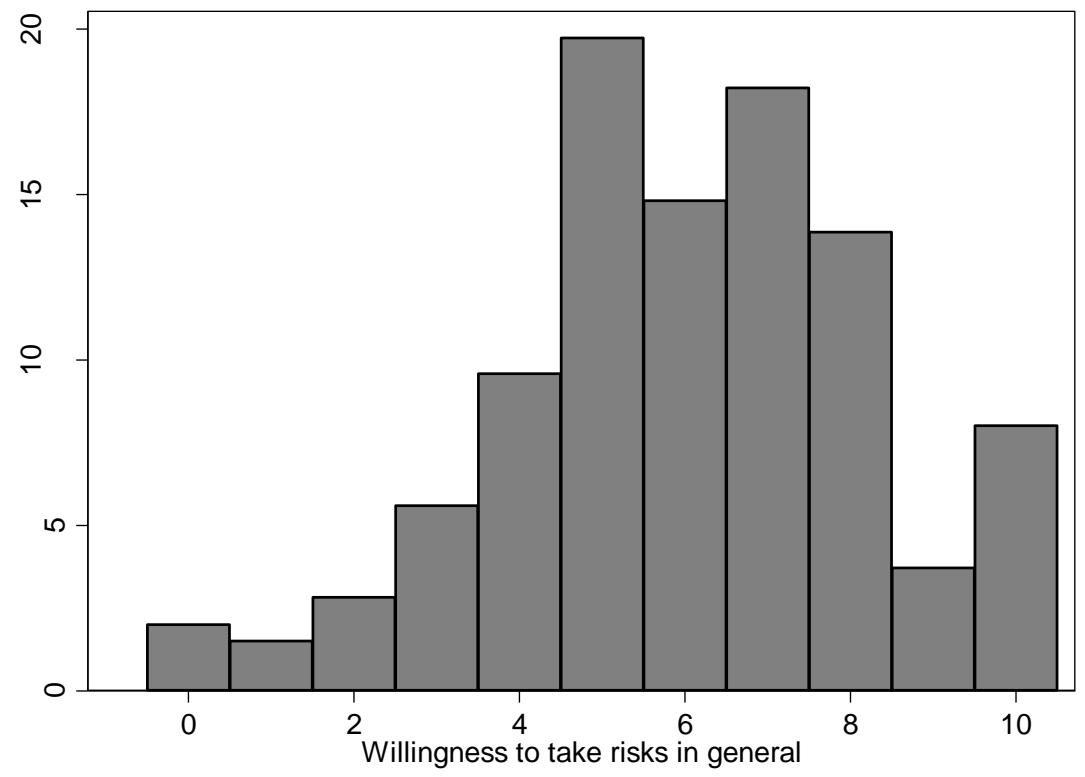

Figure 2: Histogram for the self-reported willingness to take risks in general 


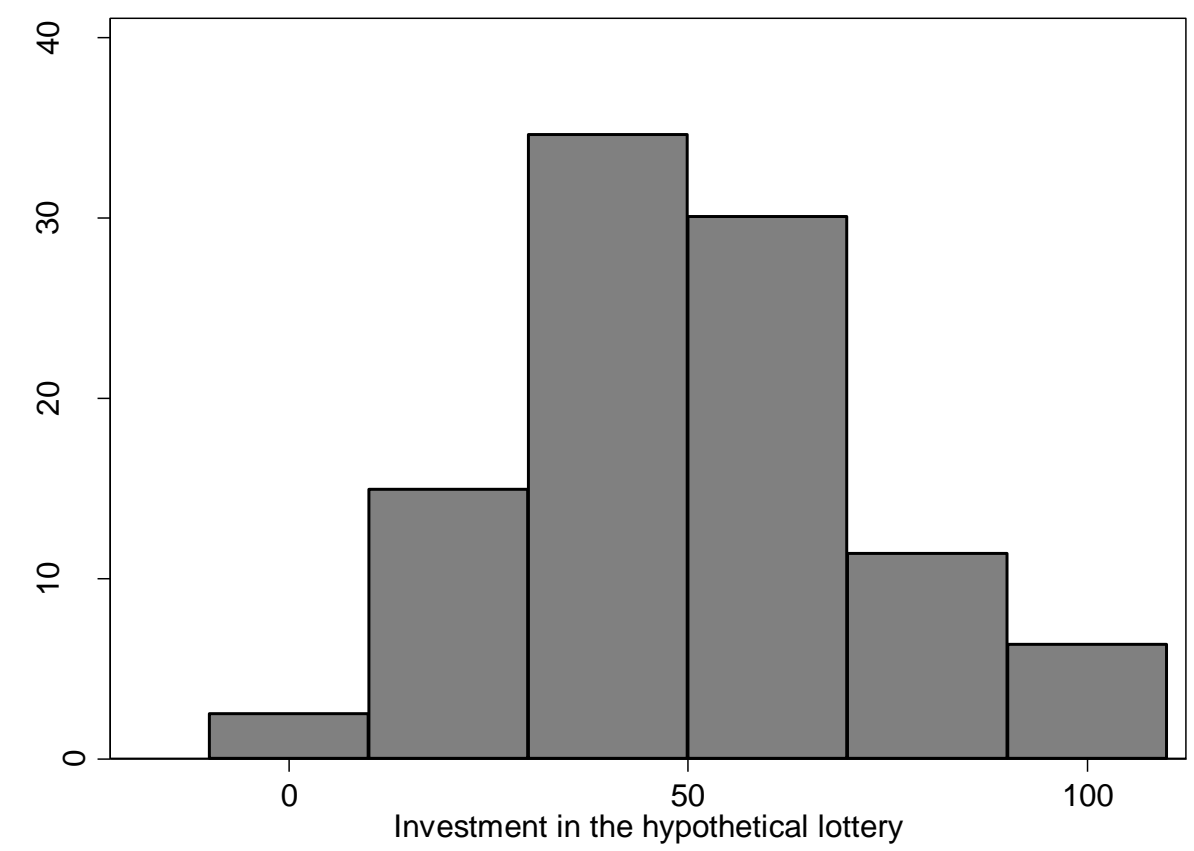

Figure 3: Histogram for the investment (as \% of the endowment) in the hypothetical lottery

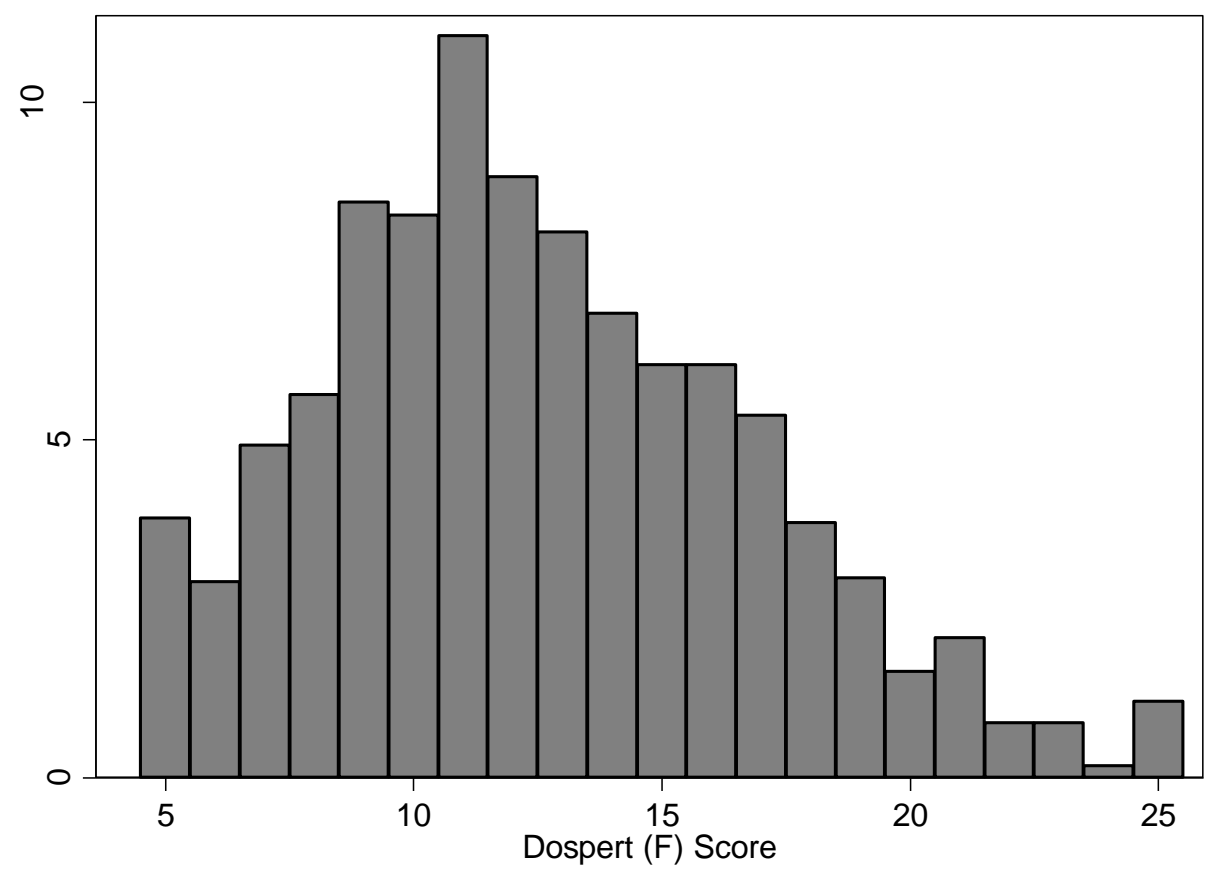

Figure 4: Histogram for the score in the financial sub-scale of DOSPERT 


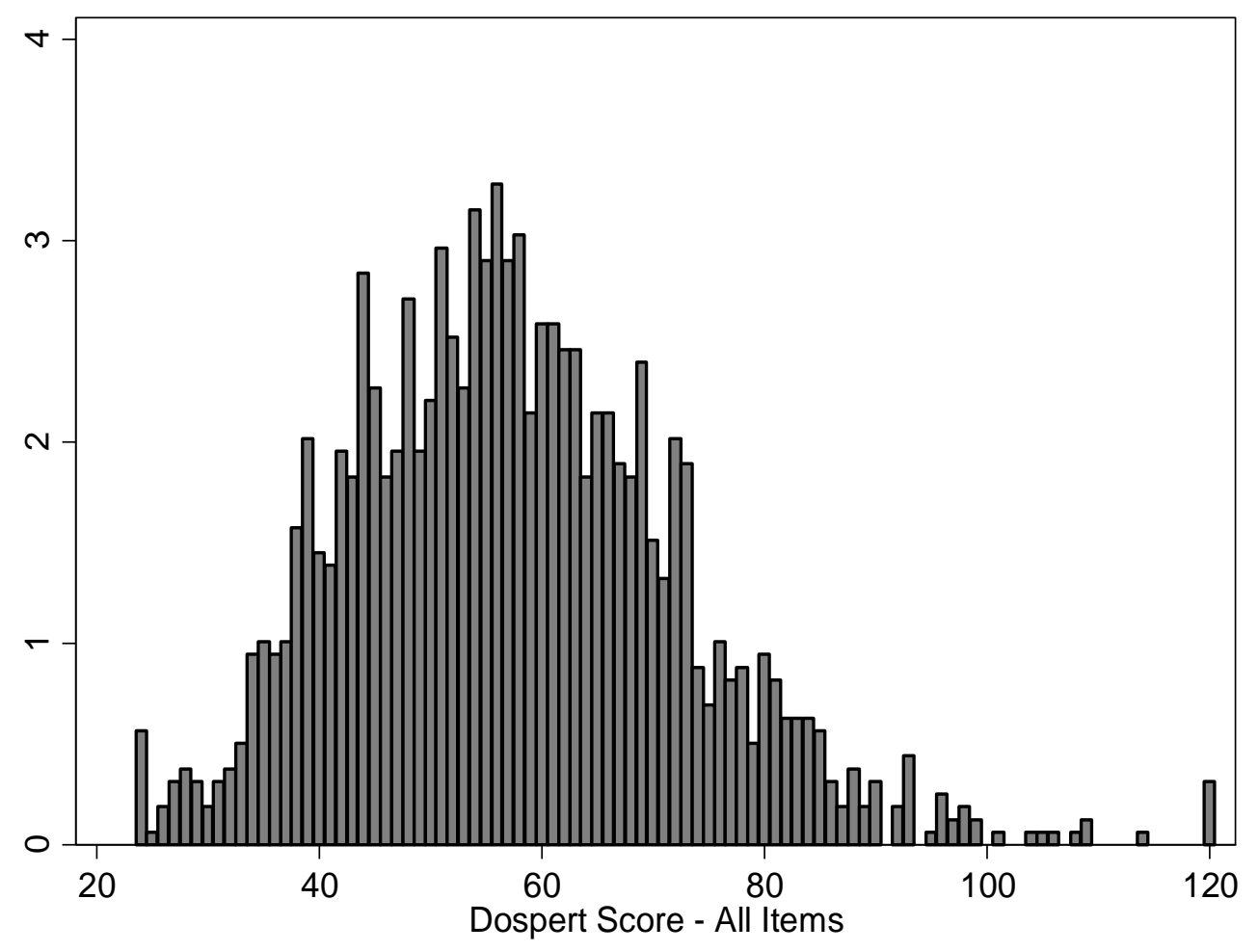

Figure 5: Histogram for the score on DOSPERT - All Items 
Table 1: Summary Statistics on the Turkish Pension Fund System

\begin{tabular}{ll}
\hline Gender & $\%$ \\
Women & 39.6 \\
Men & 60.4 \\
\hline Age Distribution & $\%$ \\
Under 25 years old & 6.32 \\
25-34 years old & 34.81 \\
35-44 years old & 33.91 \\
45-55 years old & 19.79 \\
over 56 years old & 5.16 \\
\hline Allocation in Stocks & $\%$ \\
2008 & 9.1 \\
2009 & 7.8 \\
2010 & 11.3 \\
2011 & 13.4 \\
2012 & 16.2 \\
2013 & 15.3 \\
2014 & 14.1 \\
\hline \multirow{2}{*}{ Amount of Funds } & Average \\
Contribution (Month) & $5880 \mathrm{TL}$ \\
\hline
\end{tabular}

Note: This table presents the summary statistics for the private pension system in Turkey. The data was obtained from the Individual Pension System Progress Report (2014) published by the Pension Monitoring Center. Participants who stay in the system form at least 10 years can retire at age 56 but not earlier. 


\begin{tabular}{|c|c|}
\hline Variable & Description \\
\hline average annual equity allocation & Annual average of the equity share in new (monthly) contributions in year t. \\
\hline equity investment & $\begin{array}{l}\text { Indicator variable that equals one if average annual equity share is greater } \\
\text { than } 0 \text { in year } t \text {, zero otherwise. }\end{array}$ \\
\hline$r_{b r e t}$ & Boxes collected in the Bomb Risk Elicitation Task (BRET); range is 0-100. \\
\hline$r_{\text {soep }}$ & Self-reported willingness to take risks, range is $0-10$. \\
\hline rlottery & $\begin{array}{l}\text { The investment in the hypothetical lottery as percentage of the endowment; } \\
\text { range is } 0-100 \text {. }\end{array}$ \\
\hline$r_{\text {dospert }(F)}$ & $\begin{array}{l}\text { Score in the financial subscale of the Domain-Specific Risk-Taking } \\
\text { (DOSPERT) scale; range is } 5-25 \text {. }\end{array}$ \\
\hline$r_{\text {dospert }}$ & $\begin{array}{l}\text { Overall score in the Domain-Specific Risk-Taking (DOSPERT) scale, range } \\
\text { is } 5-120 .\end{array}$ \\
\hline Gender & Indicator variable that equals one if the participant is male, zero if female. \\
\hline Age & Age of the participant in the beginning of year $t$. \\
\hline Marital Status & Indicator variable that equals one if the participant is married, zero if single. \\
\hline Log of contributions & Logarithm of the average of the monthly contributions in year t. \\
\hline Administrative status & $\begin{array}{l}\text { Indicator variable that equals to one if the participant works in an } \\
\text { administrative position in the year of the survey/experiment, zero otherwise. }\end{array}$ \\
\hline Age (2014) & Age of the participant in the year of the survey/experiment. \\
\hline College & $\begin{array}{l}\text { Indicator variable that equals to one if the participant's education level is } \\
\text { college or higher, zero otherwise. }\end{array}$ \\
\hline
\end{tabular}


Table 3: Descriptive Statistics on Demographics and Risk Attitudes

\begin{tabular}{|c|c|c|c|c|c|c|}
\hline & Obs. & Percent & Mean & Std. Dev. & Min & Max \\
\hline Male & 1585 & 39 & & & & \\
\hline Age (as of January 1, 2014) & 1583 & & 32.53 & 6.51 & 20 & 64 \\
\hline Married & 1585 & 66 & & & & \\
\hline Boxed collected in the BRET & 1585 & & 47.90 & 27.05 & 1 & 100 \\
\hline Self-reported willingness to take risks & 1585 & & 6.02 & 2.24 & 0 & 10 \\
\hline Investment in the hypothetical Lottery & 1585 & & 50.41 & 22.91 & 0 & 100 \\
\hline DOSPERT(All Items) & 1585 & & 57.48 & 14.95 & 24 & 120 \\
\hline DOSPERT $(\mathrm{F})$ & 1585 & & 12.56 & 4.33 & 5 & 25 \\
\hline Average Monthly Contribution in 2014 (TL) & 625 & & 383.36 & 347.38 & 11.73 & 2284.63 \\
\hline
\end{tabular}

Note: This table presents the descriptive statistics for the 1,585 participants (out of 1,702) who had a retirement plan for the 2008-2014 period. The average monthly contribution is calculated only for the participants who made a contribution for 12 consecutive months in 2014. 
Table 4: Spearman Correlation Matrix: Risk Attitude Measures and Demographic Factors

\begin{tabular}{|c|c|c|c|c|c|c|c|c|c|c|}
\hline & $r_{\text {bret }}$ & $r_{\text {soep }}$ & $\boldsymbol{r}_{\text {lottery }}$ & $\boldsymbol{r}_{\text {dospert }}$ & $r_{\text {dospert }(F)}$ & Age (2014) & $\begin{array}{c}\text { Gender } \\
(\text { male }=1)\end{array}$ & $\begin{array}{c}\text { Marital Status } \\
(\text { married }=1)\end{array}$ & College & Admin \\
\hline $\boldsymbol{r}_{\text {bret }}$ & 1 & & & & & & & & & \\
\hline$r_{\text {soep }}$ & $0.3269 * * *$ & 1 & & & & & & & & \\
\hline $\boldsymbol{r}_{\text {lottery }}$ & $0.2001 * * *$ & $0.5089 * * *$ & 1 & & & & & & & \\
\hline$r_{\text {dospert }}$ & $0.1291 * * *$ & $0.4257 * * *$ & $0.2887 * * *$ & 1 & & & & & & \\
\hline$r_{\text {dospert }(F)}$ & $0.1421 * * *$ & $0.3617 * * *$ & $0.2788 * * *$ & $0.6876^{* * *}$ & 1 & & & & & \\
\hline Age (2014) & $0.0492 *$ & $-0.1075 * * *$ & $-0.0957 * * *$ & $-0.1856 * * *$ & -0.0285 & 1 & & & & \\
\hline Gender $($ male $=1)$ & -0.0118 & $0.1338 * * *$ & $0.0678 * * *$ & $0.1017 * * *$ & 0.0312 & $0.1690 * * *$ & 1 & & & \\
\hline $\begin{array}{c}\text { Marital Status } \\
(\text { married }=1)\end{array}$ & -0.0348 & $-0.0688 * * *$ & -0.0332 & $-0.1618 * * *$ & $-0.0536^{* *}$ & $0.3716 * * *$ & $0.1242 * * *$ & 1 & & \\
\hline College & -0.0028 & $-0.0928 * * *$ & -0.0206 & -0.0353 & 0.0217 & $0.2009 * * *$ & -0.0320 & $0.0651 * *$ & 1 & \\
\hline Admin & 0.0319 & $-0.0790 * * *$ & $-0.0756^{* * *}$ & $-0.0916 * * *$ & -0.0319 & $0.4016^{* * * *}$ & $0.1140 * * *$ & $0.1124 * * *$ & $0.0942 * * *$ & 1 \\
\hline
\end{tabular}

Note: Spearman correlations. $* * *, * *, *$ indicate significance levels at $1 \%, 5 \%$, and $10 \%$, respectively. 
Table 5: Average Equity Allocation in New Contributions

\begin{tabular}{lccc}
\hline & Observations & Mean & Std. Dev. \\
\hline Overall & 3571 & 0.164 & 0.188 \\
\hline Year & 376 & 0.125 & 0.132 \\
2008 & 415 & 0.088 & 0.124 \\
2009 & 450 & 0.121 & 0.139 \\
2011 & 501 & 0.206 & 0.201 \\
2012 & 579 & 0.191 & 0.208 \\
2013 & 625 & 0.188 & 0.186 \\
2014 & 625 & 0.179 & 0.194 \\
\hline Gender & & & \\
Women & 2095 & 0.142 & 0.157 \\
Men & 1476 & 0.192 & 0.207 \\
\hline Marital Status & & & \\
Married & 2781 & 0.162 & 0.183 \\
Single & 790 & 0.167 & 0.174 \\
\hline Age & & & \\
Under 25 & 48 & 0.151 & 0.154 \\
25-34 & 1523 & 0.177 & 0.198 \\
35-44 & 1692 & 0.152 & 0.162 \\
45-55 & 300 & 0.158 & 0.195 \\
56 or older & 8 & 0 & 0 \\
\hline & & &
\end{tabular}

Notes: This table reports the statistics for the annual averages of the equity allocation in new contributions. For a given year, the annual average is calculated only if the participant made a contribution in all 12 months of that year. 
Table 6: Risk Attitude Measures and Demographic Factors: OLS Estimation Results

\begin{tabular}{|c|c|c|c|c|c|}
\hline Dependent Variable & $r_{b r e t}$ & $r_{\text {soep }}$ & $r_{\text {lottery }}$ & $r_{\text {dospert }(F)}$ & $r_{\text {dospert }}$ \\
\hline Gender $($ male $=1)$ & $\begin{array}{l}-0.912 \\
(1.334)\end{array}$ & $\begin{array}{l}\mathbf{0 . 7 0 5} * * * \\
(0.116)\end{array}$ & $\begin{array}{l}3.337 * * \\
(1.231)\end{array}$ & $\begin{array}{l}0.280 \\
(0.229)\end{array}$ & $\begin{array}{l}\text { 4.131*** } \\
(0.772)\end{array}$ \\
\hline Age (2014) & $\begin{array}{l}\mathbf{0 . 2 6 1} * \\
(0.129)\end{array}$ & $\begin{array}{l}\mathbf{- 0 . 0 2 5 9 *} \\
(0.0113)\end{array}$ & $\begin{array}{l}\mathbf{- 0 . 2 6 5 *} \\
(0.111)\end{array}$ & $\begin{array}{l}-0.0230 \\
(0.0202)\end{array}$ & $\begin{array}{l}-\mathbf{0 . 3 5 8} * * * \\
(0.0686)\end{array}$ \\
\hline Marital status(married=1) & $\begin{array}{l}\mathbf{- 3 . 1 3 7 *} \\
(1.513)\end{array}$ & $\begin{array}{l}-0.202 \\
(0.127)\end{array}$ & $\begin{array}{l}-1.145 \\
(1.315)\end{array}$ & $\begin{array}{l}-0.407 \\
(0.254)\end{array}$ & $\begin{array}{l}\mathbf{- 3 . 4 7 1} * * * \\
(0.849)\end{array}$ \\
\hline College ( $=1$ if $>=$ college $)$ & $\begin{array}{l}-0.712 \\
(1.912)\end{array}$ & $\begin{array}{l}-\mathbf{0 . 3 4 0} * \\
(0.168)\end{array}$ & $\begin{array}{l}-0.180 \\
(1.586)\end{array}$ & $\begin{array}{l}0.174 \\
(0.325)\end{array}$ & $\begin{array}{l}0.284 \\
(1.108)\end{array}$ \\
\hline Administrative status & $\begin{array}{l}0.885 \\
(1.847)\end{array}$ & $\begin{array}{l}-0.380 * \\
(0.167)\end{array}$ & $\begin{array}{l}-3.672 * \\
(1.684)\end{array}$ & $\begin{array}{l}-0.511 \\
(0.307)\end{array}$ & $\begin{array}{l}-1.477 \\
(1.051)\end{array}$ \\
\hline Average contribution (log) & $\begin{array}{l}-0.882 \\
(0.991)\end{array}$ & $\begin{array}{l}-0.0164 \\
(0.0847)\end{array}$ & $\begin{array}{l}0.960 \\
(0.906)\end{array}$ & $\begin{array}{l}\mathbf{0 . 6 1 8} * * * * \\
(0.177)\end{array}$ & $\begin{array}{l}0.872 \\
(0.640)\end{array}$ \\
\hline Constant & $\begin{array}{l}\text { 44.61**** } \\
(5.436)\end{array}$ & $\begin{array}{l}\text { 7.108**** } \\
(0.454)\end{array}$ & $\begin{array}{l}\mathbf{5 3 . 8 9} * * * \\
(4.661)\end{array}$ & $\begin{array}{l}\text { 10.24**** } \\
(0.924)\end{array}$ & $\begin{array}{l}\text { 65.15*** } \\
(3.277)\end{array}$ \\
\hline $\begin{array}{l}\text { N.of.Obs. } \\
\text { F-statistic } \\
\text { Prob > F } \\
\text { R-squared }\end{array}$ & $\begin{array}{l}1495 \\
1.315 \\
0.2471 \\
0.006\end{array}$ & $\begin{array}{l}1495 \\
10.55 \\
0.000 \\
0.042\end{array}$ & $\begin{array}{l}1495 \\
4.019 \\
0.0005 \\
0.016\end{array}$ & $\begin{array}{l}1495 \\
3.288 \\
0.0032 \\
0.013\end{array}$ & $\begin{array}{l}1495 \\
15.92 \\
0.000 \\
0.058\end{array}$ \\
\hline
\end{tabular}

Note: The table presents conditional OLS estimation results for different risk attitude measures. Variable definitions are provided in Table 5. Following Crosetto and Flippin (2013), subjects who made inconsistent choices in the BRET are excluded from the sample. Robust standard errors are in parenthesis. $(* * *),\left(*^{*}\right)$ and $(*)$ indicate significance at $0.01,0.05$ and 0.1 , respectively. 
Table 7: Equity Investment: Probit Regression Results

Dependent Variable: Equity Investment (0: No Equity Investment, 1: Equity Investment >0)

\begin{tabular}{|c|c|c|c|c|c|c|}
\hline & $\mathbf{I}$ & II & III & IV & $\mathbf{V}$ & VI \\
\hline$r_{b r e t}$ & $\begin{array}{c}0.000580 \\
(0.000544)\end{array}$ & & & & & $\begin{array}{l}-0.000409 \\
(0.000580)\end{array}$ \\
\hline$r_{\text {soep }}$ & & $\begin{array}{c}\mathbf{0 . 0 2 8 0} * * * \\
(0.00627)\end{array}$ & & & & $\begin{array}{l}\mathbf{0 . 0 2 5 3} * * \\
(0.00779)\end{array}$ \\
\hline rlottery & & & $\begin{array}{l}\mathbf{0 . 0 0 1 6 2} * * \\
(0.000591)\end{array}$ & & & $\begin{array}{c}0.000344 \\
(0.000661)\end{array}$ \\
\hline$r_{\text {dospert }(F)}$ & & & & $\begin{array}{c}\mathbf{0 . 0 0 8 8 9} * * \\
(0.00313)\end{array}$ & & $\begin{array}{c}0.00460 \\
(0.00329)\end{array}$ \\
\hline$r_{\text {dospert }}$ & & & & & $\begin{array}{c}0.00167 \\
(0.000987)\end{array}$ & \\
\hline Marital status(married=1) & $\begin{array}{c}0.0245 \\
(0.0354)\end{array}$ & $\begin{array}{c}0.0236 \\
(0.0344)\end{array}$ & $\begin{array}{c}0.0232 \\
(0.0350)\end{array}$ & $\begin{array}{c}0.0285 \\
(0.0350)\end{array}$ & $\begin{array}{c}0.0283 \\
(0.0354)\end{array}$ & $\begin{array}{c}0.0251 \\
(0.0344)\end{array}$ \\
\hline Age & $\begin{array}{c}\mathbf{- 0 . 0 0 6 6 3} * * \\
(0.00254)\end{array}$ & $\begin{array}{c}-\mathbf{0 . 0 0 6 2 3} * \\
(0.00251)\end{array}$ & $\begin{array}{c}-\mathbf{0 . 0 0 6 7 5} * * \\
(0.00257)\end{array}$ & $\begin{array}{l}\mathbf{- 0 . 0 0 6 5 6 *} \\
(0.00257)\end{array}$ & $\begin{array}{c}\mathbf{- 0 . 0 0 6 2 7 *} \\
(0.00257)\end{array}$ & $\begin{array}{c}-\mathbf{0 . 0 0 6 2 6 *} \\
(0.00255)\end{array}$ \\
\hline Gender $($ male $=1)$ & $\begin{array}{l}0.00675 \\
(0.0265)\end{array}$ & $\begin{array}{l}-0.0182 \\
(0.0270)\end{array}$ & $\begin{array}{c}-0.000214 \\
(0.0265)\end{array}$ & $\begin{array}{l}0.00327 \\
(0.0263)\end{array}$ & $\begin{array}{l}-0.00176 \\
(0.0270)\end{array}$ & $\begin{array}{l}-0.0189 \\
(0.0271)\end{array}$ \\
\hline College $(=1$ if $>=$ college $)$ & $\begin{array}{l}-0.0576 \\
(0.0428)\end{array}$ & $\begin{array}{l}-0.0344 \\
(0.0449)\end{array}$ & $\begin{array}{l}-0.0588 \\
(0.0423)\end{array}$ & $\begin{array}{l}-0.0609 \\
(0.0425)\end{array}$ & $\begin{array}{l}-0.0581 \\
(0.0431)\end{array}$ & $\begin{array}{l}-0.0383 \\
(0.0444)\end{array}$ \\
\hline Contribution (log) & $\begin{array}{c}\mathbf{0 . 0 9 4 0} * * * \\
(0.0199)\end{array}$ & $\begin{array}{c}\mathbf{0 . 0 9 6 8 * * * *} \\
(0.0194)\end{array}$ & $\begin{array}{c}\mathbf{0 . 0 9 5 6}^{* * * *} \\
(0.0198)\end{array}$ & $\begin{array}{c}\mathbf{0 . 0 9 0 2} * * * \\
(0.0197)\end{array}$ & $\begin{array}{c}\mathbf{0 . 0 9 5 1} * * * * \\
(0.0198)\end{array}$ & $\begin{array}{c}\mathbf{0 . 0 9 5 0} * * * * \\
(0.0195)\end{array}$ \\
\hline Time fixed effects & Yes & Yes & Yes & Yes & Yes & Yes \\
\hline N.of.Obs. & 3403 & 3403 & 3403 & 3403 & 3403 & 3403 \\
\hline Wald & 125.6 & 127.37 & 139.68 & 129.15 & 131.84 & 143.58 \\
\hline Prob $>$ Chi2 & 0.000 & 0.000 & 0.000 & 0.000 & 0.000 & 0.000 \\
\hline Pseudo R-squared & 0.038 & 0.039 & 0.055 & 0.044 & 0.044 & 0.058 \\
\hline
\end{tabular}

Note: The table presents results from Probit estimations under alternative specifications. Variable definitions are provided in Table 5. Following Crosetto and Flippin (2013), subjects who made inconsistent choices in the BRET are excluded from the sample. Marginal effects of the variables are reported. All regressions include time fixed effects. Standard errors (in parentheses) are clustered at the participant level. (***), (**) and (*) indicate significance at $0.01,0.05$ and 0.1 , respectively. 
Table 8: Equity Allocation conditional on Equity Investment: Truncated Regression Results

Dependent Variable: Average Annual Equity Allocation (percentage)

\begin{tabular}{|c|c|c|c|c|c|c|}
\hline & I & II & III & IV & $\mathbf{V}$ & VI \\
\hline$r_{\text {bret }}$ & $\begin{array}{c}0.0340 \\
(0.0212)\end{array}$ & & & & & $\begin{array}{l}-0.0106 \\
(0.0223)\end{array}$ \\
\hline$r_{\text {soep }}$ & & $\begin{array}{c}\mathbf{1 . 4 0 9} * * * \\
(0.263)\end{array}$ & & & & $\begin{array}{c}1.200 * * * \\
(0.342)\end{array}$ \\
\hline rlottery & & & $\begin{array}{c}\mathbf{0 . 0 8 6 8} * * \\
(0.0267)\end{array}$ & & & $\begin{array}{c}0.0292 \\
(0.0313)\end{array}$ \\
\hline$r_{\text {dospert }(F)}$ & & & & $\begin{array}{c}\mathbf{0 . 3 6 5} * * \\
(0.121)\end{array}$ & & $\begin{array}{c}0.139 \\
(0.139)\end{array}$ \\
\hline$r_{\text {dospert }}$ & & & & & $\begin{array}{l}\mathbf{0 . 1 0 1} * * \\
(0.0386)\end{array}$ & \\
\hline Marital status(married=1) & $\begin{array}{l}-0.138 \\
-1.202\end{array}$ & $\begin{array}{l}-0.189 \\
-1.184\end{array}$ & $\begin{array}{l}-0.268 \\
-1.194\end{array}$ & $\begin{array}{c}-0.0760 \\
-1.197\end{array}$ & $\begin{array}{l}0.0326 \\
-1.215\end{array}$ & $\begin{array}{l}-0.139 \\
-1.180\end{array}$ \\
\hline Age & $\begin{array}{l}-0.229 * \\
(0.0939)\end{array}$ & $\begin{array}{l}-0.227 * \\
(0.0894)\end{array}$ & $\begin{array}{l}-0.222 * \\
(0.0891)\end{array}$ & $\begin{array}{l}-0.220 * \\
(0.0927)\end{array}$ & $\begin{array}{l}-0.197 * \\
(0.0922)\end{array}$ & $\begin{array}{l}-0.223^{*} \\
(0.0890)\end{array}$ \\
\hline Gender $($ male $=1)$ & $\begin{array}{l}\mathbf{5 . 8 0 4} * * * \\
-1.147\end{array}$ & $\begin{array}{l}\mathbf{4 . 4 0 9} * * * * \\
-1.089\end{array}$ & $\begin{array}{l}\mathbf{5 . 2 6 7} * * * \\
-1.078\end{array}$ & $\begin{array}{l}\mathbf{5 . 7 0 9} * * * \\
-1.132\end{array}$ & $\begin{array}{c}\mathbf{5 . 2 5 4} * * * \\
-1.134\end{array}$ & $\begin{array}{l}\mathbf{4 . 3 8 0} * * * \\
-1.087\end{array}$ \\
\hline College $(=1$ if $>=$ college $)$ & $\begin{array}{l}-3.768 \\
-2.172\end{array}$ & $\begin{array}{l}-2.812 \\
-2.002\end{array}$ & $\begin{array}{l}-3.989 \\
-2.223\end{array}$ & $\begin{array}{l}-4.114 \\
-2.236\end{array}$ & $\begin{array}{l}-3.977 \\
-2.188\end{array}$ & $\begin{array}{l}-3.173 \\
-2.050\end{array}$ \\
\hline Contribution (log) & $\begin{array}{l}\mathbf{1 . 8 4 5} * \\
(0.764)\end{array}$ & $\begin{array}{c}\mathbf{2 . 0 1 8} * * \\
(0.729)\end{array}$ & $\begin{array}{c}1.986 * * \\
(0.740)\end{array}$ & $\begin{array}{l}\mathbf{1 . 7 5 7} * \\
(0.760)\end{array}$ & $\begin{array}{l}1.925 * \\
(0.760)\end{array}$ & $\begin{array}{c}\mathbf{2 . 0 0 0} * * \\
(0.732)\end{array}$ \\
\hline Time fixed effects & Yes & Yes & Yes & Yes & Yes & Yes \\
\hline $\begin{array}{l}\text { N.of.Obs. } \\
\text { Wald } \\
\text { Prob > Chi2 }\end{array}$ & $\begin{array}{l}2560 \\
40.99 \\
0.000\end{array}$ & $\begin{array}{l}2560 \\
49.02 \\
0.000\end{array}$ & $\begin{array}{r}2560 \\
44.06 \\
0.000\end{array}$ & $\begin{array}{l}2560 \\
43.14 \\
0.000\end{array}$ & $\begin{array}{l}2560 \\
42.08 \\
0.000\end{array}$ & $\begin{array}{l}2560 \\
50.92 \\
0.000\end{array}$ \\
\hline
\end{tabular}

Note: The table presents results from truncated regressions under alternative specifications. Following Crosetto and Flippin (2013), subjects who made inconsistent choices in the BRET are excluded from the sample. Conditional marginal effects are reported. Variable definitions are provided in Table 5. All regressions include time fixed effects. Standard errors (in parentheses) are clustered at the participant level. $(* * *),(* *)$ and $(*)$ indicate significance at 0.01 , 0.05 and 0.1 , respectively. 
Table 9: Combined Marginal Effects from the Two-Part Model

Dependent Variable: Average Annual Equity Allocation (percentage)

\begin{tabular}{|c|c|c|c|c|c|c|}
\hline & $\mathbf{I}$ & II & III & IV & $\mathbf{V}$ & VI \\
\hline$r_{\text {bret }}$ & $\begin{array}{l}0.0375 \\
(1.84)\end{array}$ & & & & & $\begin{array}{l}-0.0177 \\
(-0.81)\end{array}$ \\
\hline$r_{\text {soep }}$ & & $\begin{array}{l}\mathbf{1 . 6 2 4 * * * *} \\
(6.85)\end{array}$ & & & & $\begin{array}{l}1.402 * * * \\
(4.62)\end{array}$ \\
\hline rlottery & & & $\begin{array}{l}\mathbf{0 . 1 0 2} * * * \\
(4.05)\end{array}$ & & & $\begin{array}{l}0.0322 \\
(1.10)\end{array}$ \\
\hline$r_{\text {dospert }(F)}$ & & & & $\begin{array}{l}\mathbf{0 . 4 6 7 * * *} \\
(3.99)\end{array}$ & & $\begin{array}{l}0.206 \\
(1.60)\end{array}$ \\
\hline$r_{\text {dospert }}$ & & & & & $\begin{array}{l}\mathbf{0 . 1 1 5} * * \\
(3.03)\end{array}$ & \\
\hline Marital status(married=1) & $\begin{array}{l}0.406 \\
(0.34)\end{array}$ & $\begin{array}{l}0.395 \\
(0.34)\end{array}$ & $\begin{array}{l}0.284 \\
(0.24)\end{array}$ & $\begin{array}{l}0.544 \\
(0.47)\end{array}$ & $\begin{array}{l}0.636 \\
(0.53)\end{array}$ & $\begin{array}{l}0.445 \\
(0.39)\end{array}$ \\
\hline Age & $\begin{array}{l}-\mathbf{0 . 3 2 0} * * * \\
(-3.52)\end{array}$ & $\begin{array}{l}\mathbf{- 0 . 3 0 2} * * * \\
(-3.43)\end{array}$ & $\begin{array}{l}-\mathbf{0 . 3 1 6} * * * \\
(-3.55)\end{array}$ & $\begin{array}{l}-\mathbf{0 . 3 0 9} * * * \\
(-3.41)\end{array}$ & $\begin{array}{l}\mathbf{- 0 . 2 8 5} * * \\
(-3.15)\end{array}$ & $\begin{array}{l}-\mathbf{0 . 2 9 9} * * * \\
(-3.38)\end{array}$ \\
\hline Gender $($ male $=1)$ & $\begin{array}{l}\text { 4.569**** } \\
(4.39)\end{array}$ & $\begin{array}{l}\mathbf{3 . 0 4 6}^{* *} * \\
(2.99)\end{array}$ & $\begin{array}{l}\mathbf{4 . 0 4 9} * * * \\
(4.02)\end{array}$ & $\begin{array}{l}\mathbf{4 . 4 2 7} * * * * \\
(4.30)\end{array}$ & $\begin{array}{l}3.982 * * * \\
(3.82)\end{array}$ & $\begin{array}{l}\mathbf{3 . 0 1 7} * * \\
(2.96)\end{array}$ \\
\hline College $(=1$ if $>=$ college $)$ & $\begin{array}{l}-4.263^{*} \\
(-2.05)\end{array}$ & $\begin{array}{l}-3.050 \\
(-1.52)\end{array}$ & $\begin{array}{l}-\mathbf{4 . 4 1 1} * \\
(-2.11)\end{array}$ & $\begin{array}{l}-4.586^{*} \\
(-2.20)\end{array}$ & $\begin{array}{l}-\mathbf{4 . 4 4 3} * \\
(-2.14)\end{array}$ & $\begin{array}{l}-3.371 \\
(-1.67)\end{array}$ \\
\hline Contribution (log) & $\begin{array}{l}3.328 * * * \\
(4.59)\end{array}$ & $\begin{array}{l}3.487 * * * \\
(4.99)\end{array}$ & $\begin{array}{l}3.453 * * * \\
(4.88)\end{array}$ & $\begin{array}{l}3.178 * * * \\
(4.43)\end{array}$ & $\begin{array}{l}3.404 * * * \\
(4.73)\end{array}$ & $\begin{array}{l}\text { 3.430**** } \\
(4.89)\end{array}$ \\
\hline Time fixed effects & Yes & Yes & Yes & Yes & Yes & Yes \\
\hline N.of.Obs. & 3403 & 3403 & 3403 & 3403 & 3403 & 3403 \\
\hline
\end{tabular}

Note: The table presents average marginal effects from the combined probit and truncated regressions under alternative specifications. Estimation is implemented using Stata "twopm" routine. Following Crosetto and Flippin (2013), subjects who made inconsistent choices in the BRET are excluded from the sample. Variable definitions are provided in Table 5. All regressions include time fixed effects. Robust z-statistics are (in parentheses) are clustered at the participant level. $(* * *),(* *)$ and $(*)$ indicate significance at $0.01,0.05$ and 0.1 , respectively. 